\title{
Lunar Farming: Achieving Maximum Yield for the Exploration of Space
}

\author{
Frank B. Salisbury \\ Plants, Soils and Biometeorology, Utah State University, Logan, UT 84322-4820
}

So, you want to visit the CELSS farms here in Luna City? I'm a farmer in that facility, and I'd be happy to show them to you. Perhaps we can complete our visit before midnight, when the year 2020 begins. (Because the lunar day is 29.530589 Earth days long, we keep Greenwich Earth time here.) As a matter of fact, we can celebrate New Year's Eve with a meal in the mess hall based almost entirely on food from the CELSS farms. What is the significance of the CELSS acronym, you ask? It stands for Controlled Ecological (or Environment) Life-Support System. Fundamentally, it is a bioregenerative life-support system (which could be called BLISS!).

On our way to the farms, let's make a brief stop in the Earth-observation room. From our location here in the Sea of Serenity, Earth hangs in a black sky $60^{\circ}$ above the horizon and slightly west of south. It is always there! With a diameter 3.67 times and an area almost 14 times that of the moon as it appears from Earth, Earth is truly a spectacular sight in the sky. It is fascinating to watch it go through its phases. The Earth is always full at lunar midnight, and it was full on Christmas this year (2019). When the sun appears close to the Earth, the Earth is a thin crescent: a new Earth. Once or twice a year, the sun moves behind the Earth, producing an eclipse. The sun's rays, refracted by Earth's atmosphere, form a red ring around the Earth; a circular sunset, one might say, that produces a red glow here on the moon. It's fascinating to watch the Earth rotate and to observe cyclones and other storms moving across its surface.

As everyone knows, our CELSS farms in Luna City are based on photosynthesis in which carbon dioxide, water, and minerals are transformed with the help of light energy into food and oxygen. The water transpired by the plants is condensed in pure form, providing much more water than the inhabitants of Luna City actually need. Furthermore, the

Received for publication 7 Feb. 1991. This work was supported in part by Utah State Experiment Station Project 283 and by National Aeronautics and Space Administration grant NAG10-0073. This is Experiment Station technical paper 4129.

This work was presented as the William A. (Tex) Frazier Lecture at the 87th Annual Meeting of the American Society for Horticultural Science, Tucson, Ariz., 4 Nov. 1990.

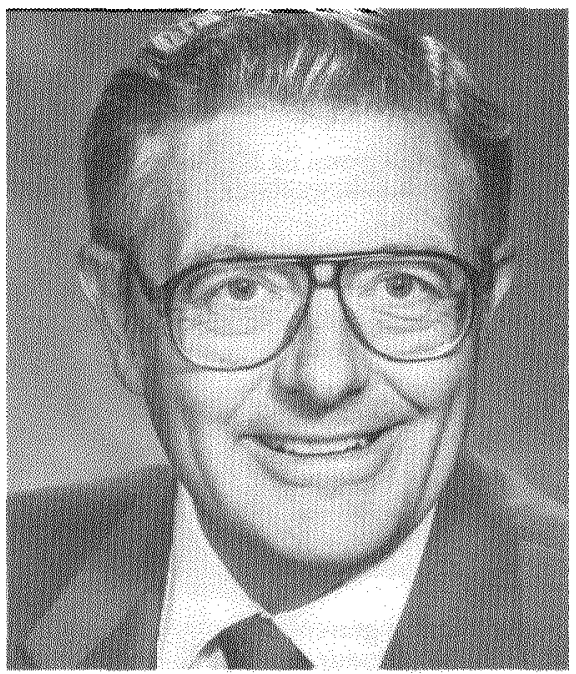

Frank B. Salisbury

plants produce a pleasant and familiar environment for us Earthlings. An important part of the CELSS system combines inedible plant parts and other wastes with oxygen from photosynthesis to produce carbon dioxide, water, and minerals, partially completing the cycle. Of course our bodies are also part of the system, as we breathe oxygen and consume the food and water that is produced, releasing $\mathrm{CO}_{2}$ as we respire.

Before our CELSS was fully developed, we had only physical/chemical methods of waste disposal available, and their limitations prevented a complete recycling. Lithium hydroxide $(\mathrm{LiOH})$ was used to remove $\mathrm{CO}_{2}$, but it did not provide oxygen and thus was not part of a recycling system. (Lithium peroxide had the potential of releasing $\mathrm{O}_{2}$ as it absorbed $\mathrm{CO}_{2}$, but its use also presented problems.) Most wastes were simply dried and stored or sometimes jettisoned. Water was condensed and purified in various ways, but even that proved to be more difficult than had been expected; now our plants do a better job of filtering the water as it passes through them into the atmosphere. There is no physical/chemical way to recycle food.

It was always clear from basic principles that plants and microorganisms could play an important role in a recycling system in a space craft, on the moon, or on Mars, but could they compete with physical/chemical processes combined with periodic resupply from Earth? A study carried out in 1981 sug- gested that the launch weight of a CELSS would about equal the launch mass of a physical/chemical system combined with resupply after about 7 years. By 1986, we had learned enough about optimizing plant growth so that a subsequent calculation suggested a break-even time (see Fig. 1) of only a little less than 3 years (Mason, 1980; Oleson and Olson, 1986). Putting some of the principles that I've alluded to into practice, as well as others I'll be telling you about as we tour the CELSS farms, allowed the construction of Luna City beginning about 15 years ago. We have about 250 people living here now, and all of them eat a carefully balanced diet, most of it coming from the lunar farms. These farms include a wide variety of crops and even a small livestock colony with a few chickens and fish (tilapia, carp, and trout) that eat the plant materials that are not wellsuited for humans.

A group at Purdue Univ., West Lafayette, Ind., (Hoff et al., 1982) studied various crops according to a series of criteria related to their suitability for a CELSS farm (Table 1). Table 2 lists the crops with the highest scores based on these criteria. Many of them, plus a few others that proved to be as good or better (based on more recent information), are grown in our lunar farms.

\section{The lunar CELSS farms}

Let's visit the farms. I'll explain things as we go. Way back in the 1980 s, when these things were being planned, artists depicted what they imagined the future farms would be like (Paine, 1986). Huge glass domes sat on the moon's surface with field crops and orchards growing underneath. It was a beautiful dream, but it was incompatible with the facts of the lunar environment (Mendell, 1985). Radiation from solar flares that come at intervals is lethal to humans and plants that are not suitably protected. With a lunar day lasting 29.53 Earth days, plants that depend on sunlight would have to survive about 15 days of darkness interspersed with 14 days of light. While experiments showed that many plants could actually tolerate such a cycle, they were certainly not very productive in these conditions (G.M. Lisovskii, Institute of Biophysics, Krasnoyarsk, USSR, personal communication). The vacuum of space on the lunar surface made large transparent structures extremely difficult to build. If pressure on the inside of such a structure 
times the world record for the field.

A decrease in efficiency accompanied the increase in yield with increasing irradiance (Fig. 2). Nevertheless, efficiency at the lowest irradiance was $10 \%$, integrated over the entire life cycle. Photosynthetic efficiencies (conversion of light energy to chemical bond energy) during the period of maximum growth must have closely approached the calculated maximum efficiencies for photosynthesis, $\approx 13 \%$, suggesting, as indicated above, that only light was limiting and that all other environmental factors were at or close to their optimum levels.

The data on yield and efficiency point up some important CELSS trade-offs (Fig. 3). Less light means a higher efficiency of photosynthetic conversion and thus a somewhat lower power requirement, but more light means a smaller farm. In our experiment, at the highest light levels, a human being could be provided with food on a continuous basis in a CELSS farm only about $13 \mathrm{~m}^{2}$ in area, about the size of an office! Even with a safety factor of as much as 4 to allow for other crops that might be less productive or have a lower harvest index, or both, and even for an occasional crop failure, a CELSS farm should not have to exceed $\approx 50 \mathrm{~m}^{2} /$ person. At this rate, a farm the size of an American football field $\left(5000 \mathrm{~m}^{2}\right)$ could support about 100 people.

According to the law of limiting and optimum factors, when everything is at its optimum, plants can achieve maximum yield. We can define stress as any condition that results in less-than-maximum yield. Because our wheat yielded five times the world-record, we must conclude that the wheat plants in that world-record field were under stress.

However, the situation is not quite so straightforward. Table 4 shows yields of wheat in the record field compared with yields of our CELSS wheat. It turns out to be difficult to estimate the world-record yields because we do not know the length of the life cycle nor the density of planting. The reasonable. estimates shown in the table suggest that, while the CELSS wheat canopy yielded nearly five times as much as the world-record canopy, individual plants may have yielded only slightly less in the world-record field. In short, the high yields that we obtained in a controlled environment occurred because the high planting density allowed good use of the resources that considerably exceeded their counterparts in the world-record field: 2.5 times as much total light as wheat plants could possibly have received in the field, 3.6 times as much $\mathrm{CO}_{2}$, virtually no water stress, optimized mineral nutrients, and an ideal temperature. The dense canopy allowed full use of these resources. There is no way to know how much light was absorbed by the individual plants in the CELSS canopy compared with those in the world-record field, but the data in Table 4 suggest that each individual plant in the CELSS canopy may have received even less light than comparable plants in the field (because they were packed together so tightly), and that the

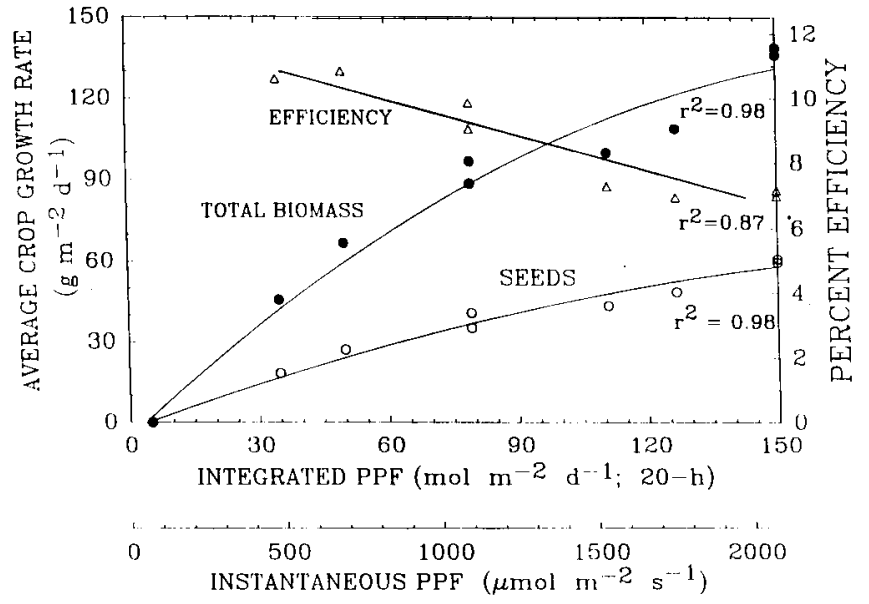

Fig. 2. Average crop growth rate (total biomass and biomass of seed, which is edible grain) and percent efficiency (chemical-bond energy of total biomass as percent of input light energy) as a function of irradiance applied to wheat plants in a controlled environment. Irradiance is shown as instantaneous photosynthetic photon flux (PPF: flux of photons that are effective in photosynthesis; $2000 \mu \mathrm{mol} \cdot \mathrm{m}^{-2} \cdot \mathrm{s}^{-1}=$ full sunlight) and PPF integrated over the 20-h day (Bugbee and Salisbury, 1988).

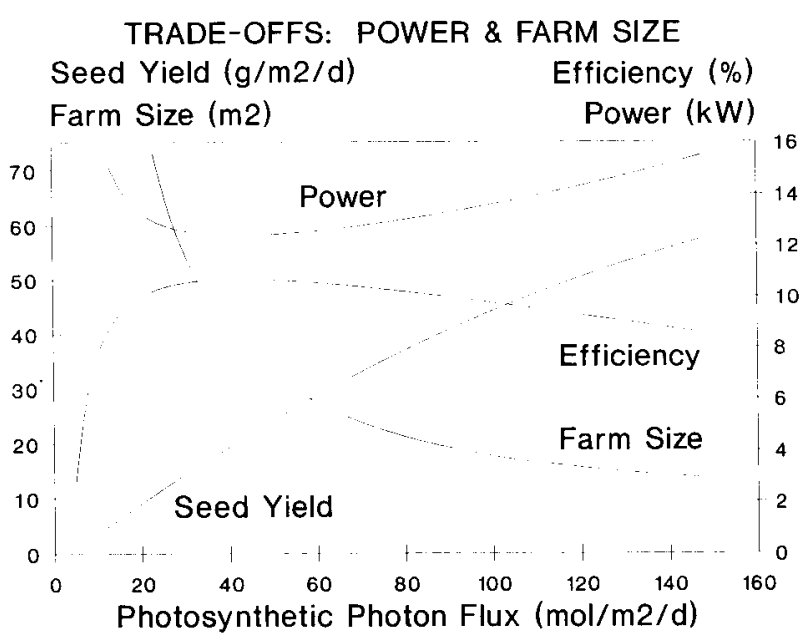

Fig. 3. Illustrating trade-offs between farm size and power requirement for a CELSS, based on yield and efficiency as a function of irradiance (PPF). Farm size is calculated directly from the yield curve, based on an assumed energy requirement of a human of $11,700 \mathrm{~kJ} \cdot \mathrm{day}^{-1}$ and an energy content of oven-dried wheat of $15,000 \mathrm{~kJ} \cdot \mathrm{kg}^{-1}$. Power requirement is calculated from the efficiency curve, but includes some assumptions about the efficiency of conversion of electrical to light energy.

Table 4. Data on world-record and CELSS wheat yields. Were world-record wheat plants under stress?

Data on world-record wheat (Kittitas County, Washington, U.S.A., 1965): ${ }^{x}$

Cultivar: Gaines, winter wheat.

Field size and yield: English units: 2.2 acres, 27,600 pounds, 209 bushels per acre.

SI units: $0.89 \mathrm{ha}, 12,517 \mathrm{~kg}=1406 \mathrm{~g} \cdot \mathrm{m}^{-2}$.

Assume growing season is 100 to 120 days, yield $\approx 12$ to $14 \mathrm{~g} \cdot \mathrm{m}^{-2}$.day ${ }^{-1}$.

Seed yield per plant.

Assume 200 plants $/ \mathrm{m}^{2}: 7 \mathrm{~g} /$ plant.

Assume 600 plants $/ \mathrm{m}^{2}: 2.33 \mathrm{~g} /$ plant.

Daily yield: 0.0194 to $0.07 \mathrm{~g}$ /day per plant.

Utah CELSS wheat (Bugbee and Salisbury, 1988), yields:

Cultivar: Yecora Rojo, hard red spring wheat.

Growing conditions: growth chamber $\left(0.8 \mathrm{~m}^{2}\right.$; harvested area $\left.=0.228 \mathrm{~m}^{2}\right) ; 20 \mathrm{C}$ day, $15 \mathrm{C}$

night; $2000 \mu \mathrm{mol} \cdot \mathrm{s}^{-1} \cdot \mathrm{m}^{-2} ; \mathrm{CO}_{2}=1200 \pm 30 \mu \mathrm{mol} \cdot \mathrm{mol}^{-1}(\mathrm{ppm})$, hydroponic medium.

Seed yield:

$4760 \mathrm{~g} \cdot \mathrm{m}^{-2}$ in $79 \mathrm{~d}=60 \mathrm{~g} \cdot \mathrm{m}^{-2} \cdot \mathrm{day}^{-1}$.

2000 plants $/ \mathrm{m}^{2}=2.37 \mathrm{~g} /$ plant.

Daily yield: $0.03 \mathrm{~g} /$ day per plant.

Complication: It is impossible to know the amount of light absorbed per plant in the two situations.

${ }^{2}$ Data from a letter from P.E. Bloom, County Extension Agent, Kittitas county, to R. Bertramson, Dept. of Agronomy, Washington State Univ., Pullman, 29 Oct. 1965. 
Table 2. continued.

\begin{tabular}{lc}
\hline \hline Common name & $\begin{array}{c}\text { Estimated } \\
\text { value }\end{array}$ \\
\hline Strawberry (Fragaria ×ananussa) & 39 \\
Watermelon (Citrullus lunatus) & 28 \\
Herbs and spices & \\
Anise (Pimpinella anisum) & \\
Basil (Ocimum basilicum) & \\
Caraway (Carum carvi) & \\
Chili peppers (Capsicum annuum) & \\
Dill (Anethum graveolens) & \\
Garlic (Allium sativum) & \\
Mint (Mentha arvensis) & \\
Mustard (Brassica nigra) & \\
Oil cropsw & \\
Cotton seed (Gossypium hirsutum) & \\
Peanuts (Arachis hypogaea) & \\
Rape seed (Brassica napus) & \\
Soybeans (Glycine max) & \\
Sunflowers (Helianthus annuus) & \\
\hline
\end{tabular}

${ }^{x}$ Extracted from: J.E. Hoff, J.M. Howe, and C.A. Mitchell (1982). The authors are at Purdue Univ., West Lafayette, Ind., and the report was prepared for NASA Ames Research Center, Moffett Field, Calif. Exotic crops will probably also be considered for use in a CELSS (Vietmeyer, 1986), but they are arbitrarily not considered in this article.

${ }^{y}$ See Table 1 for a description of criteria used in crop selection.

${ }^{x}$ Herbs and spices were listed but not evaluated in the Purdue study. The selection shown here is completely arbitrary.

"It is important to grow some crops just for the oil, although oil-seed crops were not considered as such in the Purdue study. The ones shown here all have high yields and would be suitable for growth in controlled environments. Soybeans and peanuts are also shown as food legumes; they are an excellent source of protein as well as oil.

Back in the 1980s, there was some controversy about whether plants should be grown hydroponically or whether the lunar regolith should be used as a substrate, developing it gradually into a true soil as organic matter built up (Ming and Henninger, 1989). Such an approach would allow the "soil" to be part of the waste disposal system, but, in so doing, significant quantities of carbon would be tied up in the organic matter; there were also significant penalties in yield. As it turned out, there are many advantages to hydroponics (Bugbee and Salisbury, 1989). Nutrient availability and composition are subject to accurate control in a hydroponic system, and root-zone oxygen can be kept at suitable levels. Water potential never drops low enough to be stressful, and $\mathrm{pH}$ can be controlled accurately. The proof of the approach lies in the root : shoot ratio. If the plant can obtain ample water, nutrients, and oxygen, relatively little of its biomass is partitioned to the roots. Indeed, a wheat crop in a good hydroponic system may have only $3 \%$ or $4 \%$ of its dry biomass as roots; this compares with $20 \%$ to $40 \%$ in the field (Bugbee and Salisbury, 1988).

A critical point in designing a CELSS is the concept of buffer size. On Earth, $\mathrm{CO}_{2}$ in the atmosphere is buffered by all the $\mathrm{CO}_{2}$ and carbonates dissolved in the hydrosphere, but CELSS buffers are minuscule compared with this. Thus, precise levels of $\mathrm{CO}_{2}$ and other substances must be maintained by active control rather than depending on buffering. This applies to the nutrient medium, oxygen levels, and virtually everything that is critical for growth of plants in the CELSS and for the well-being of the human inhabitants.

Plant pathogens can be a problem in a CELSS, partially because planting densities and atmospheric humidities are typically very high. The problems are minimized by compartmentalizing the environments, an approach that is also needed to provide optimum environments for different crops. Resistant cultivars are used, but chemical control is a problem in the closed environment. Ultraviolet and ionizing radiation are used in the duct work to keep pathogen levels down. We also construct artificial microbial communities that provide the proper balance of organisms to help control pathogens, and we use the most modern monitoring techniques, including infrared observations, monoclinal antibodies, and other biotechnology systems.

Back in the 1990s, we wondered whether we should have a large crop variety or just a few staples such as soybeans, potatoes, and wheat, calling upon food technology to create many foods from these basic plant materials. We soon realized that plants make many tasty, nutritious molecules, and that a variety of plants offers certain psychological advantages that, while they are not easy to measure, are nevertheless real. Thus, we have the large variety of crops noted (Table 2).

\section{The total CELSS}

Our lunar CELSS has four functioning parts: 1) A plant-production facility with higher plants and algae; 2) food technology kitchens; 3) waste processing and recycling facilities; 4) control systems.
We have been discussing several aspects of the plant-production facility. The primary goal of the kitchens is to provide a balanced, attractive diet that includes ample food energy. A secondary goal is to use inedible plant parts. For example, the cellulose in straw is broken down by cellulase enzymes obtained from fungi, and the resulting glucose is used in various ways (including some fermentation into alcohol! ). Another secondary goal is to recover as much nitrogen as possible before unused plant parts are sent to the recycling facilities, where much fixed nitrogen is released to the atmosphere. First, soluble salts are removed by soaking the plant material in water, then other processes (developed in the late 1990s) are also applied. Blue-green algae (cyanobacteria) are used to fix some of the nitrogen lost in food preparation and waste recycling.

Science fiction authors have suggested that we might emulate plants by synthesizing food from scratch: from carbon dioxide, water, and minerals. Research in this field was going on as early as the mid-1980s, particularly in Japan, where purified enzymes were being used (Nitta, 1987). But machinery and energy costs proved to be very high, and again it was realized that plants do an excellent and relatively inexpensive job.

Our waste disposal system uses both physical/chemical and biological techniques. While it is difficult to synthesize food and only plants can really do it, it is less difficult to go in the opposite direction and break it down. Incineration is one approach, with the ash being converted to plant nutrients, but the smoke is a problem that must be solved with filters and catalytic converters. Research was just beginning in the 1990s. Super-critical water oxidation is another approach. At $374 \mathrm{C}$ and above, and pressures of $22 \mathrm{MPa}$ or above, water, organic liquids and solids, gaseous oxygen, and nitrogen all become miscible with each other. The organics are oxidized, and the ash settles and can be converted to plant nutrients. Such a system requires considerable energy, but we recover some of this energy with a turbine in the effluent stream.

As we've noted already, loss of fixed nitrogen is a problem. We use chemical nitrogen fixation (the Haber-Bosch process), but this requires much energy. Thus, we also use biological nitrogen fixation with free-living microorganisms, as well as Rhizobium nodules on legumes.

The waste disposal trade-offs involve energy and carbon. If plenty of energy is available (as from a nuclear reactor), physical systems are basically a good choice. Otherwise, biological waste disposal systems can be used, but they tie up much carbon, which allows oxygen to build up. Remember that all the carbon must come from Earth.

Our control systems respond to sensors located throughout Luna City, their outputs being fed to a central computer with a backup system and an independent power supply. 
We use intrinsic feedback loops when possible: If $\mathrm{CO}_{2}$ drops and oxygen rises, we oxidize more wastes, for example. If oxygen begins to drop while $\mathrm{CO}_{2}$ builds up, we increase the light on the plants to increase photosynthesis. Nevertheless, leaks are a constant problem, so some control is provided by gasses released from storage.

To reduce the human workload, it is essential for the CELSS to make maximum use of automation and robotics. This allows most of the inhabitants of Luna City to be engaged in activities other than farming. Some study the geology of the moon, observe the universe (astronomy), do other scientific research, process lunar regolith for oxygen, mine the regolith for helium-3 (for fusion reactors), and engage in other activities.

So far, we have been talking about a Lunar CELSS; the one-sixth of earth's gravity makes things much simpler than they are in a microgravity space craft. Some of my colleagues are in a spaceship out among the asteroids prospecting for minerals. An initial goal was to simplify some of the engineering by operating the spaceship in microgravity. (Although the term microgravity is now widely used, we usually deal with milli gravity on a space craft. Crew activities and functioning machinery produce random accelerational forces of about $10^{-3}$ times Earth's gravity.) There are problems with handling solutions in microgravity, but these can be managed. Plant gravitropism is also a bit of a problem. Generally, plants orient their stems and roots in relation to the gravitational field, but they can also orient their shoots (usually not their roots) toward a point source of light. By the 1980s, several other adverse effects of microgravity on plants had been reported (Halstead and Dutcher, 1987), but some of these were artifacts of the poor environments used to grow the plants in space. However, animals also responded poorly to microgravity, and humans were as sensitive as any other animal. Calcium loss from bones was a problem (Roux, 1983). The obvious solution was to spin the spacecraft and produce an artificial gravity. Thus, my colleagues out among the astroids are not living in a microgravity environment after all. The only microgravity CELSS is a small, experimental one in the Space Station Freedom, which is orbiting Earth.

Other colleagues of mine are establishing a colony on the surface of Mars. Although it's a long trip to get there, conditions are somewhat more benign than they are on the moon. There is a thin atmosphere (about $1 \%$ of earth's atmosphere), which allows parachute landings. There is also about 20 times as much $\mathrm{CO}_{2}$ in that atmosphere as in Earth's atmosphere. Irradiance levels vary with the seasons and in the highly elliptical orbit of Mars around the sun from about $37 \%$ to $52 \%$ of the irradiance here on the moon. The Martian day is just a little over $24 \mathrm{~h}$, which is certainly advantageous, and, while water is difficult to obtain on Mars, it is present. There is oxygen in the silicate rocks, the same as here on the moon. Temperature fluctuates drastically between day and night, but is always very cold ( $-75 \mathrm{C}$ at night to $20 \mathrm{C}$ at noon in the summer on the equator at the soil surface). Several characteristics on earth, in the space station, on the moon, and on Mars are compared in Table 3.

\section{What we knew about plant productivity by 1990}

NASA was interested in the CELSS concept as early as 1960 , but, after sporadically supporting some research for a few years, NASA lost interest. Beginning in about 1978 to 1979 , this interest was rekindled, and various plant productivity and other projects were supported during the 1980s. [Wheat, Frank B. Salisbury and Bruce G. Bugbee, Utah State Univ.; potatoes, Theodore (Ted) W. Tibbitts, Univ. of Wisconsin, Madison; lettuce and, recently, a few other crops, Cary A. Mitchell, Purdue Univ.; soybeans, David Raper, North Carolina State Univ.; sweetpotatoes, a more-recently funded team at Tuskegee Institute; and two smaller projects on algae (Salisbury and Bugbee, 1988).] The level of support was relatively low (probably less than $\$ 30$ million for the total periodcompared with a cost of nearly 10 times that much for a single launch of the space shuttle!). The Soviets also began supporting CELSS research around 1960, but they continued their efforts until the present.

The Soviet program was located at various institutes around the Soviet Union, but the Institute of Biophysics in Krasnoyarsk in central Siberia was especially active (Ivanov and Zubareva, 1985). In the early 1960s, the Soviets began their studies with the alga Chlorella, but they discovered that it "made but poor food for man" (Terskov et al., 1986). They then began to use higher plants, emphasizing wheat, chufa nut sedge (related to purple nut sedge, the world's worst weed; it has an oil-containing tuber), and several other vegetables. They made many advances in growing these crops in controlled environments, and several of these advances have been applied in Soviet agriculture, particularly in the far north. Yosev I. Gitleson was Director of the Institute of Biophysics and Genry M. Lisovsky was Deputy Director. In 1972, the group constructed Bios-3. They

Table 3. Space environments.

\begin{tabular}{lcccc}
\hline \hline & \multicolumn{4}{c}{ Location } \\
\cline { 2 - 5 } Factor & Earth & Space station & Moon & Mars \\
\hline Gravity & 1.0 & $<0.001$ & 0.165 & 0.38 \\
Day length & $24 \mathrm{~h}$ & $90 \mathrm{~min}$ & 29.530589 days & $\begin{array}{c}24 \mathrm{~h} \mathrm{39} \mathrm{min} \\
35 \mathrm{sec}\end{array}$ \\
Year & 365.25 days & Same & Same & $\begin{array}{c}687 \text { Earth } \\
\text { days }\end{array}$ \\
$\begin{array}{c}\text { Tilt of axis } \\
\text { (season) }\end{array}$ & $23.5^{\circ}$ & & $1.5^{\circ}$ & $25^{\circ}$ \\
$\begin{array}{c}\text { Atmospheric } \\
\text { pressure }\end{array}$ & $101.3 \mathrm{kPa}$ & Artificial & none & $1.0 \mathrm{kPa}$ \\
Light (\% of Earth) & $100 \%$ & $100 \%$ & $100 \%$ & $37 \%$ to $52 \%$ \\
\hline
\end{tabular}

carried out experiments with the facility from 1972 to 1985 . Two or three volunteers from the Institute were sealed in the unit for 4 to 6 months at a time, with a total experiment

Bios- 3 consisted of welded, stainless-steel plates enclosing a volume of about $300 \mathrm{~m}$ and about $63 \mathrm{~m}^{2}$ of growing space for plants. Only a few sealable ports connected the inside with the outside world, and the only input was electric current and television programs. They estimated the leak rate at about 30 to 150 liters $\cdot \operatorname{day}^{-1}(0.01 \%$ to $0.05 \% /$ day $)$.

Bios-3 had four equal-sized compartments. Two of these were used for wheat, one for the other vegetables, and the fourth was further subdivided into living quarters, kitchen, laboratory, waste disposal systems, and the control console. Vegetables that were grown included table beets, carrots, dill, turnips, cabbage, radishes, cucumbers, peas, kohlrabi, leeks, and the chufa sedge. The plants supplied $80 \%$ of the caloric intake for the subjects, and the other $20 \%$ was taken in at the beginning of each run, primarily in the form of frozen meat. The subjects chose their own diets, which were virtually identical to their normal diets. They were under constant medical supervision, and their body weights stayed within $\pm 800 \mathrm{~g}$. Plants were grown hydroponically, and urine was added directly to the nutrient solution. Thermocatalytic filters were used to purify the air, and straw and other plant-waste products were burned in an incinerator. The ash and human solid waste were stored until the end of each run.

The system never achieved complete stability. Sodium accumulated in the nutrient solutions and in the plants. The microflora (bacteria and other organisms) were carefully monitored, but did not stabilize. Hence, the CELSS concept was demonstrated, but only for relatively brief intervals of time. An ideal CELSS required a much better waste disposal system.

Way back in Sept. 1989 and Apr. 1990 (when I was very young!), I was able to visit the Institute of Biophysics in Krasnoyarsk. The first opportunity was a meeting arranged primarily with the scientists at Biosphere-2, and the second meeting involved people from NASA. We Americans and a few others from Western Europe (in the first meeting) found the scientists in Krasnoyarsk to be not only time of about 2 years.

Light $(\%$ of Earth)


highly capable, but also extremely friendly and willing to share their results with us. Glasnost was real !

Speaking of Biosphere 2, this was a huge structure that was almost complete in late 1990 in the Arizona desert some $50 \mathrm{~km}$ north of Tucson. About 1 ha was enclosed under glass, and the structure was sealed as tightly as possible. It was sealed on the bottom (below the soil, plumbing, etc.) with stainlesssteel plates. The cost by late 1990 had reached $\$ 100$ million. In common with Bios-3 and a NASA CELSS built in the mid-1990s, Biosphere 2 had the goal of achieving stability in a closed ecological system. The approach was quite different from that of CELSS and Bios-3, however. About 4000 species (including eight male and female humans: "Biospherians") were introduced in an attempt to duplicate seven of the earth's biomes. (Earth was called Biosphere 1.) In addition to a massive cooling system (environmental control), they had hoped to achieve a stability based on natural feed-back systems built on the huge variety of organisms (plus active intervention from the Biospherians), whereas our Lunar CELSS cannot afford the luxury of many inedible organisms and must use technological control systems to maintain balances and control conditions. Biosphere 2 proved to be an interesting experiment, but we won't review the results (first obtained in the early 1990s) here.

\section{Plant productivity in a CELSS}

Because of the extreme limitations on mass and energy (it costs several thousands of dollars to launch $1 \mathrm{~kg}$ of mass into space), space farming must be highly efficient. Crops must be harvested as soon as they are mature, and as soon as one crop is harvested the next one is planted in its place. Thus, the measure of productivity is yield per unit area per day, usually grams per square meter per day. Eventually, volume had to be taken into consideration, but to a considerable extent that was an engineering problem rather than an agronomic one.

Figure 1 is a generalized dose-response curve. Essential elements or environmental factors can be limiting when they are present in less-than-optimum amounts. Once the optimum has been achieved, further increases in the factor often lead to no further increases in yield; this is luxury consumption. When concentrations or intensities are too high, yields may be decreased; this is toxicity. Justus Liebig stated the principle in 1840: "The growth of a plant is dependent on the amount of 'food stuff' presented to it in minimum quantities." Victor Shelford, in 1913, generalized the concept further, including the idea of super-optimal or toxic quantities: "Each and every plant species is able to exist and reproduce successfully only within a certain range of environmental conditions."

With these ideas in mind, one approach is to establish all environmental factors at their optimum levels, except light, which can then

THE BASIC DOSE-RESPONSE CURVE

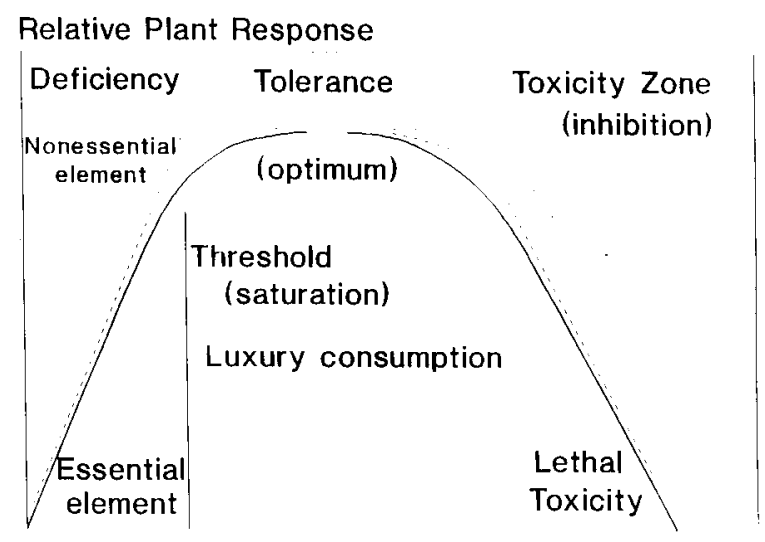

Dose (factor level)

Fig. 1. A generalized dose-response curve showing an organism's response to an environmental resource. The curve is three-phased, with zones of deficiency, tolerance, and toxicity or inhibition. Note that a nonessential factor can be toxic at high levels. Minimum, optimum, and maximum (only optimum is shown) are called cardinal points. Typically, there is a wide zone of tolerance; because additional amounts of the resource in this zone do not induce additional plant response (typically, yield), we speak of luxury consumption (from Salisbury and Ross, 1991).

be varied. The environmental factors that must be considered include water, carbon dioxide, temperature, nutrient medium, planting density, and genetics (cultivar). Based on what is known about photosynthesis, it is possible to make calculations about expected yields based on the light that is absorbed. If actual yields are close to the expected ones, then it can reasonably be assumed that all environmental factors are close to their optimum levels, with productivity being limited only by the light energy that is absorbed.

A small calculation illustrates some of these points and puts the question of CELSS yields into perspective. One hundred grams of ovendry wheat has about $1500 \mathrm{~kJ}(370 \mathrm{kcal})$. Let us say a human needs $11,700 \mathrm{~kJ} \cdot \mathrm{day}-{ }^{1}$; this could be satisfied by $780 \mathrm{~g}$ of oven-dried wheat/day. If the farm has an area of $15 \mathrm{~m}^{2}$, then it must produce $52 \mathrm{~g} \cdot \mathrm{m}^{-2} \cdot$ day $^{-1}$ of ovendry wheat or its caloric equivalent to support one human.

\section{The Utah wheat project}

The project was initiated in 1981 with Bruce G. Bugbee as a postdoctoral fellow; in 1987, he became principal investigator. Three small (0.8- $\mathrm{m}^{2}$ growing area), state-of-the-art growth chambers were purchased and modified for this research. These chambers provided irradiance levels equivalent to half of sunlight in two chambers and full sunlight in one chamber $\left(2000 \mu \mathrm{mol} \cdot \mathrm{m}^{-2} \cdot \mathrm{s}^{-1}\right)$. Temperature, humidity, and air velocity were controlled, carbon dioxide was enriched (usually to $1200 \mu \mathrm{mol} \cdot \mathrm{mol}^{-1}$ ), and plants were grown in a flowing-liquid hydroponic medium. There was also a greenhouse bay with enriched $\mathrm{CO}_{2}$, relatively accurate temperature control (water running over the glass), and supplementary light from high-pressure sodium lamps. In 1990, a walk-in growth room was added in which near-solar light levels from high-pres- sure sodium lamps were combined with accurate temperature control in an area larger than that available in the growth chambers $\left(\approx 9 \mathrm{~m}^{2}\right)$.

The greenhouse bay was used largely for cultivar trials, and, by 1990 , more than 1000 culivars had been tested in controlled, optimized environments. The goal was to combine high productivity with short height (35 $\mathrm{cm}$ or less), and some effort was expended to find uniculm types (so planting densities could be high, quickly forming a canopy). Several strains that were uniculm in the field formed profuse tillers in the optimized environments. There was a great difference in yield depending upon cultivar, with some cultivars yielding two or three times as much in controlled environments as others, although nearly all were high-yielding cultivars in the field.

Initial studies used a relatively high temperature $(27 \mathrm{C})$ to shorten the life cycle and thus produce a smaller number in the denominator and a larger number for yield per square meter per day. The life cycle was decreased from $\approx 120$ days in the field to $\approx 59$, and yields were certainly encouraging: 24 $\mathrm{g} \cdot \mathrm{m}^{-2} \cdot$ day $^{-1}$ compared with a world-record yield of $\approx 12$ to $14 \mathrm{~g} \cdot \mathrm{m}^{-2} \cdot \mathrm{day}^{-1}$. Unfortunately, however, the harvest index was only $\approx 24 \%$ compared with $45 \%$ in the field. Because of the relatively high temperatures, heads were simply not filling with grain. Hence, temperature was reduced to 20C day/ $15 \mathrm{C}$ night, and a short darkperiod $(4 \mathrm{~h})$ was added and combined with a high planting density (2000 plants $\left./ \mathrm{m}^{2}\right)$ and irradiance from 400 to $\left.2000 \mu \mathrm{mol} \cdot \mathrm{m}^{-2} \cdot \mathrm{s}^{-1}\right)$, maintained at a constant level for the 20-h photoperiod (Bugbee and Salisbury, 1988). The life cycle increased to 79 days, but the yield on a daily basis almost tripled to $60 \mathrm{~g} \cdot \mathrm{m}^{-2} \cdot \mathrm{day}^{-1}$ (at the highest irradiance)! This was almost five 
equalled atmospheric pressure at sea level on Earth, it would exceed that on the outside by $10,332.3 \mathrm{~kg} \cdot \mathrm{m}^{-2}$. Of course, such pressure differences are the rule in any pressurized spacecraft (and in pressurized aircraft), but their size and shape make the engineering problems much easier to solve. A large transparent dome, tens to hundreds of meters in diameter and pressurized for humans inside, poses infinitely more formidable engineering problems. Hence, Luna City is mostly underground. Tubular modules were brought from earth and covered with about $3 \mathrm{~m}$ of lunar regolith. The modules are interconnected, but capable of being individually and rapidly sealed against sudden leaks, which could be disastrous to Luna City. Small leaks are unavoidable, so the atmosphere of Luna City must be continually regenerated from the lunar regolith itself (it is relatively easy to obtain oxygen from the regolith) or brought in pressurized containers from Earth at great expense. Because there is virtually no carbon on the moon, carbon or carbon compounds, including certain foods (especially meat), must be brought from Earth with some regularity.

Let me tell you about these CELSS farms. Most of the light for photosynthesis is artificial. The lamps are powered with a coldfusion nuclear reactor manufactured in Utah! (Well, maybe it's a hot-fusion reactor; I'll have to check one of these days to be sure.) In spite of being underground, we try to use sunlight during the lunar day to save some power. It is collected in huge Fresnel lenses and brought into the farms via fiber optics (as in a system developed by the Himawari Company in Japan back in the 1980s). The system is about $60 \%$ efficient $(60 \%$ of the light energy is transmitted to the plants). (Solar cells with batteries for storage are about $7 \%$ to $14 \%$ efficient.)

Transpired water is condensed in large coils that are exposed to the cold radiant environment of space but shielded from sunlight. With such a system, it is easier to condense the water than it is on Earth, where compressors are needed for cooling. Much of the water is recycled to the plants; some of it is purified further for use by the humans and animals.

Although plants photosynthesize somewhat better when oxygen is reduced to low levels, not enough is gained to make this approach worthwhile. If we used low oxygen levels, we farmers would have to wear masks with supplemental oxygen when we worked with the plants.

However, humans tolerate higher $\mathrm{CO}_{2}$ levels than plants, so we must carefully monitor the rate at which gasses from the farms are circulated from the living and working quarters to the farms and back again. Carbon dioxide is held at about four times its ambient level in Earth's atmosphere in the 1990s; this level promotes photosynthesis in much the same way as reduced oxygen. In the gas circulation system, toxic gasses are scrubbed out with catalytic oxidizers and active charcoal filters.
Table 1. Criteria used for evaluation of crops listed in Table 2. ${ }^{2}$

\begin{tabular}{ll}
\hline \hline Use or nutritional criteria & \multicolumn{1}{c}{ Cultural criteria } \\
\hline Energy concentration & Proportion of edible biomass \\
Nutritional composition & Yield of edible plant biomass \\
Palatability & Continuous harvestability \\
Serving size and frequency & Growth habit and morphology \\
Processing requirements & Environmental tolerance \\
Use flexibility & Photoperiod and temp. needs \\
Storage stability & Symbiotic requirements \\
Toxicity level & Response to CO and irradiance \\
Human use experience & Suitability for soilless culture \\
& Disease resistance
\end{tabular}

${ }^{2}$ Each crop was assigned a score for each criterion, the assignment often being arbitrary because of lack of data. Scores were totaled, and crops chosen for Table 2 were those that had a score of 28 or higher. The scores will change in response to future research, and several crops with scores of 27 or lower might be quite suitable for a CELSS.

Table 2. Crops grown on the moon in the year $2019^{2}$

\begin{tabular}{|c|c|}
\hline Common name & $\begin{array}{l}\text { Estimated } \\
\text { value }^{y}\end{array}$ \\
\hline \multicolumn{2}{|l|}{ Leguminous crops } \\
\hline Bean, dry or field (Phaseolus vulgaris) & 29 \\
\hline Bean, green or snap (P. vulgaris) & 29 \\
\hline Bean, mung (Vigna radiata) & 29 \\
\hline Pea, garden (Pisum sativum) & 30 \\
\hline Pea, pigeon (Cajanus cayan) & 28 \\
\hline Pea, southern, cow (Vigna unguiculata) & 29 \\
\hline Pea (sugar, Chinese) (Pisum sativum) & 29 \\
\hline Peanut (Arachis hypogaea) & 35 \\
\hline Soybean (Glycine max) & 34 \\
\hline \multicolumn{2}{|l|}{ Salad crops } \\
\hline Celery (Apium graveolens) & 31 \\
\hline Cucumber (Cucumis sativus) & 29 \\
\hline Lettuce, leaf (Lactuca sativa) & 38 \\
\hline Mushroom (Agaricus bisporus) & 28 \\
\hline Parsley (Petroselinum crispum) & 28 \\
\hline Tomato (Lycopersicon esculentum) & 37 \\
\hline \multicolumn{2}{|l|}{ Leaf and flower crops } \\
\hline Broccoli (Brassica oleracen, Italica) & 28 \\
\hline Cabbge, head (B. oleracea, Capitata) & 29 \\
\hline Chard (Beta vulgaris) & 34 \\
\hline Collards (Brassica oleracea, Acephala) & 33 \\
\hline Dandelion (Taraxacum officinale) & 28 \\
\hline Kate (Brassica oleracea, Acephala) & 34 \\
\hline Mustard greens (B. rapa, Perviridis) & 31 \\
\hline Spinach (Spinacia oleracea) & 30 \\
\hline \multicolumn{2}{|l|}{ Sugar crops } \\
\hline Sorghum (Sorghum bicolor) & 28 \\
\hline Sugar beets (Beta vulgaris) & 37 \\
\hline Sugar cane (Saccharum officinarum) & 34 \\
\hline \multicolumn{2}{|l|}{ Nut crops } \\
\hline Filbert (Corylus avellana) & 30 \\
\hline \multicolumn{2}{|l|}{ Root and tuber crops } \\
\hline Beet, garden (Beta vulgaris) & 29 \\
\hline Potato (Solanum tuberosum) & 35 \\
\hline Sweetpotato (Ipomoea batatas) & 32 \\
\hline Taro (Colocasia esculenta) & 30 \\
\hline \multicolumn{2}{|l|}{ Grain crops } \\
\hline Barley (Hordeum vulgare) & 30 \\
\hline Maize (corn) (Zea mays) & 32 \\
\hline Oats (Arena sativa) & 29 \\
\hline Rice (Oryza sativa) & 36 \\
\hline Rye (Secale cereale) & 32 \\
\hline Wheat (Triticum aestivum) & 38 \\
\hline \multicolumn{2}{|l|}{ Fruit crops } \\
\hline Banana (Musa $\times$ paradisiaca) & 35 \\
\hline Muskmelon (Cucumis melo) & 36 \\
\hline Grape, European (Vitis vinifera) & 34 \\
\hline Pineapple (Ananas comosus) & 32 \\
\hline Raspberry (Rubus idaeus) & 28 \\
\hline
\end{tabular}


slightly higher yield per plant (if it really was slightly higher) may have been a response to some of the other resources.

\section{Some caveats}

In this paper, I attempted to stay in character as a farmer on the moon in the year 2020, suggesting several features of a future Lunar CELSS. In many cases there is simply not yet enough information to be sure about these matters, so my suggestions were educated guesses (as I tried to suggest by giving dates that are still in the future in 1990). In particular, the following areas still need considerable research:

1) Will waste disposal systems be purely physical/chemical, purely biological, or a combination of both? The value of lithium peroxide as a way to absorb $\mathrm{CO}_{2}$ and release $\mathrm{O}_{2}$ has not yet been ascertained.

2) Will natural sunlight be used in a CELSS?

3) What are the effects of microgravity on plant productivity?

4) Will we use a high diversity of crops or only a few crops combined with advanced food technology?

5) What role will algae play?

6) How much food will we be able to synthesize directly from $\mathrm{CO}_{2}$, water, minerals, and some form of input energy?
7) How limited will our power supply be?

8) The postulated time for Luna City (2020) with its 250 inhabitants now looks hopelessly optimistic, based on Congressional budget actions during Sept. 1990.

\section{Literature Cited}

Bugbee, B.G. and F.B. Salisbury. 1988. Exploring the limits of crop productivity: I. Photosynthetic efficiency of wheat in high irradiance environments. Plant Physiol. 88:869-878.

Bugbee, B.G. and F.B. Salisbury. 1989. Controlled environment of crop production: Hydroponic vs. lunar regolith, p. 107-130. In: D.W. Ming and D.L. Henninger (eds.). Lunar base agriculture: Soils for plant growth. Amer. Soc. of Agronomy, Crop Science Soc. of Amer., and Soil Science Soc. of Amer., Madison, Wis.

Halstead, T.W. and F.R. Dutcher. 1987. Plants in space. Annu. Rev. Plant Physiol. 38:317345.

Hoff, J.E., J.M. Howe, and C.A. Mitchell. 1982. Nutritional and cultural aspects of plant species selection for a regenerative life support system. Purdue Univ. West Lafayette, Ind. NASA Contractor Rpt. 166324.

Ivanov, B. and O. Zubareva. 1985. To Mars and back again on board Bios. Soviet Life. Apr. p. $22-25$.

Mason, R.M. 1980. CELSS scenario analysis Breakeven calculations. NASA Contractor Rpt. 166319. Apr. 1980.

Mendell, W.W. (ed.). 1985. Lunar bases and space activities of the 21st century. Lunar and Planetary Inst., Houston.

Ming, D.W. and D.L. Henninger (eds.). 1989. Lunar base agriculture: Soils for plant growth Amer. Soc. of Agronomy, Crop Science Soc. of Amer., and Soil Science Soc. of Amer., Madison, Wis.

Nitta, K. 1987. An overview of Japanese CELSS research activities. Adv. Space Res. 7(4):95103.

Oleson, M. and R.L. Olson. 1986. Controlled ecological life support systems (CELSS) conceptual design option study. NASA Contractor Rpt. 177421, June 1986.

Paine, T. (chairman). 1986. Pioneering the space frontier: The report of the National Commission on Space. Bantam, New York.

Roux, S.J. (ed.). 1982. The regulatory functions of calcium and the potential role of calcium in mediating gravitational responses in cells and tissues. Proc. Amer. Soc. for Expt. Biol., Bethesda, Md. NASA Conf. Publ. 2286.

Salisbury, F.B. and B.G. Bugbee. 1988. Plant productivity in controlled environments. HortScience 23(2):293-299.

Salisbury, F.B. and C.W. Ross. 1991. Plant physiology. 4th ed. Wadsworth, Belmont, Calif.

Terskov, I, I. Gitelzon, B. Kovrov, and G. Lisovsky. 1986. Harvest in space. Science in the U.S.S.R. 3:42-46, 77.

Vietmeyer, N.D. 1986. Lesser-known plants of potential use in agriculture and forestry. Science 232:1379-1384. 